\title{
Liver iron concentration, stainable iron, and total body storage iron
}

\author{
MICHAEL BARRY
}

From the Department of Medicine, The Royal Free Hospital, London

SUMMARY Liver iron concentration has been determined chemically in 154 liver biopsies and the findings compared with the routine histological assessment of stainable parenchymal iron, performed by an independent observer. There was a significant correlation between liver iron concentration and histochemical grading but the relationship did not have a normal linear form. Absence of stainable iron corresponded to liver iron concentrations below the mean value for control male subjects ( $77 \mu \mathrm{g} / 100 \mathrm{mg}$ dry liver). In general grade 1 siderosis corresponded to liver iron concentrations in the upper part of the control range and grade 2 siderosis to marginally elevated values. The transition from grade 2 to grade 3 (submaximal) siderosis represented a sharp increase in liver iron concentration and as grade 3 siderosis corresponded to a wide range of chemical values it is also the most difficult histochemical grade to interpret in quantitative terms. Grade 4 siderosis invariably indicated heavy iron excess.

There was a close correlation between liver iron concentration and measurements of total body storage iron obtained by quantitative phlebotomy in patients with idiopathic haemochromatosis and by determination of DTPA-chelatable body iron in a variety of iron-loading disorders.

The liver is the principal iron storage organ of the body and liver biopsy provides definitive information about the size of the stores as well as revealing the extent of any associated liver disease. Traditionally, liver iron stores have been semiquantitatively assessed by histochemical means using the Prussian blue reaction. Although this technique is of established value the findings are not always easy to interpret, particular controversy having attached to the amount of stainable iron that can be regarded as normal.

Until about ten years ago stainable iron was regarded as an unusual finding in normal liver (Wachstein, 1963) and its presence was generally thought to represent iron excess. Subsequently, the studies of MacDonald (MacDonald and Pechet, 1964; MacDonald, 1967) have established that slight or moderate siderosis is relatively common and it has also been shown that stainable liver iron can occur in essentially healthy subjects with normal liver iron concentrations (Weinfeld, Lundin, and Lundvall, 1968). Thus, while massive iron deposition is unmistakable and provides conclusive evidence of iron excess, the significance of intermediate degrees

Received for publication 15 March 1974. of siderosis, commonly found in patients with liver disease, frequently gives rise to uncertainty.

The interpretation of stainable liver iron would be simplified if the findings could be related to some standard measurement of storage iron. On a priori grounds a general correlation with liver iron concentration might be expected and was in fact found by Weinfeld et al (1968) in subjects with normal storage values; however, Walker, Miller, Dymock, Shilkin, and Williams (1971) observed no correlation between liver iron concentration and stainable iron over a wide range of iron loading in patients with haemochromatosis. This paper describes the relationship between liver iron concentration and stainable liver cell iron in 154 biopsies examined since 1969 and also reports the relationship between liver iron concentration and quantitative measurements of total body storage iron.

\section{Materials and Methods}

In addition to the routine assessment of stainable iron, liver iron concentration has been determined in 154 liver biopsies since 1969. The clinical sources of the material are summarized in the table. Apart from six wedge biopsies and nine necropsy speci- 


\begin{tabular}{lrrrrr}
\hline & \multicolumn{5}{c}{ Hepatic Siderosis (grade) } \\
\cline { 2 - 6 } & \multicolumn{1}{c}{1} & 1 & 2 & 3 & 4 \\
\hline Idiopathic haemochromatosis & 3 & 7 & 5 & 8 & 14 \\
Thalassaemia & 0 & 0 & 2 & 6 & 18 \\
Miscellaneous haematological & 3 & 2 & 2 & 2 & 5 \\
disorders & 7 & 7 & 5 & 5 & 0 \\
Alcoholic cirrhosis & 7 & 3 & 4 & 1 & 0 \\
Non-alcoholic cirrhosis & 7 & 10 & 0 & 0 & 0 \\
Miscellaneous hepatic diseases & 2 & 4 & 0 & 0 & 0 \\
Chronic alcoholism & 7 & 7 & 1 & 0 & 0 \\
Miscellaneous medical disorders & 36 & 40 & 19 & 22 & 37 \\
Totals & & &
\end{tabular}

Table Sources of liver biopsies and histochemical gradings

mens, all were obtained by percutaneous needle biopsy using the Menghini technique. In the majority of the biopsies, including 40 referred from outside hospitals, liver iron concentration was determined prospectively as part of the investigation of patients suspected of having iron excess on clinical grounds. Some specimens were submitted to chemical analysis in the light of the histological findings and the remainder were randomly obtained from patients undergoing liver biopsy for the investigation of various hepatic and extrahepatic disorders.

Histological sections were stained by Perls' method and the stainable iron content of the parenchymal cells was graded according to the criteria of Scheuer, Williams, and Muir (1962). By this method grade 0 represents absence of stainable liver cell iron, and grades 1-4 increasing degrees of parenchymal siderosis ranging from a weakly positive Perls' reaction through to the massive iron deposition found in fully developed haemochromatosis. When the intensity of the siderosis was regarded as intermediate between two grades (usually reflecting uneven distribution) the higher value was accepted; trace amounts of stainable iron localized to a few parenchymal cells were designated as grade 1 siderosis. The presence of reticuloendothelial or septal siderosis was recorded but did not influence the grading of the specimen. The histological examinations were performed by an independent observer without knowledge of the results of the chemical analyses.

Liver total iron concentration was determined by the method of Barry and Sherlock (1971). Specimens were oven-dried and then weighed. The weight was less than $1.99 \mathrm{mg}$ in 14 specimens, 2.00 $4.99 \mathrm{mg}$ in 79 specimens, $5.00-7.99 \mathrm{mg}$ in 59 specimens, and greater than $8.00 \mathrm{mg}$ in the remainder. The dry weight of large pieces of liver has been found to be approximately $17 \%$ of the wet weight. In 28 biopsies examined in duplicate the standard error for a single determination of iron concen- tration corresponded to a coefficient of variation of $7 \cdot 2 \%$. Some specimens were received embedded in paraffin having been previously processed and sectioned for histological examination. These specimens were separated from the block by soaking in xylene and then dried. Five specimens were examined in duplicate, in the fresh state, and after histological processing respectively; the SE of the difference corresponded to a coefficient of variation of $7.0 \%$.

The relationship between liver iron concentration and total body storage iron was investigated by the technique of quantitative phlebotomy in 10 patients with idiopathic haemochromatosis undergoing therapeutic venesection. Liver iron concentration was determined in biopsies obtained before and immediately after a course of treatment consisting of two $500 \mathrm{ml}$ venesections per week until the iron stores were reduced to normal. Mobilized storage iron was calculated by standard techniques (Barry, Cartei, and Sherlock, 1969).

Liver iron concentration was also determined in 50 biopsies from patients whose total iron stores were indirectly quantified by determination of DTPA-chelatable body iron (Barry, Cartei, and Sherlock, 1970). These observations were made in 20 cases of idiopathic haemochromatosis, 11 of thalassaemia (five splenectomized and six with the spleen in situ), 10 cirrhotics, and nine patients with miscellaneous hepatic disorders.

\section{Results}

STAINABLE LIVER CELL IRON

The relationship between liver iron concentration and stainable liver cell iron is shown in figure 1. Absence of stainable iron corresponded to liver iron concentrations of 10 to $181 \mu \mathrm{g} / 100 \mathrm{mg}$ dry weight. All but three of the biopsies without parenchymal siderosis had values below the mean for London control males $(77 \mu \mathrm{g} / 100 \mathrm{mg})$ and only two had values above $100 \mu \mathrm{g} / 100 \mathrm{mg}$. The highest, in a patient with massive hepatic necrosis, was associated with prominent Kupffer cell siderosis.

Grade 1 siderosis corresponded to liver iron concentrations of 19 to $472 \mu \mathrm{g} / 100 \mathrm{mg}$ (mean 144 $\mu \mathrm{g} / 100 \mathrm{mg}$ ). The majority of the values lay between 80 and $230 \mu \mathrm{g} / 100 \mathrm{mg}$. The two biopsies with the highest values had prominent reticuloendothelial siderosis while the four with the lowest values showed scattered traces of haemosiderin only.

Grade 2 siderosis corresponded to liver iron concentrations in the range 104-1271 $\mu \mathrm{g} / 100 \mathrm{mg}$. The geometric mean $(236 \mu \mathrm{g} / 100 \mathrm{mg})$ was significantly higher $(t=2.92, \mathrm{P}<0.005)$ than that for grade 1 siderosis although the values showed considerable 


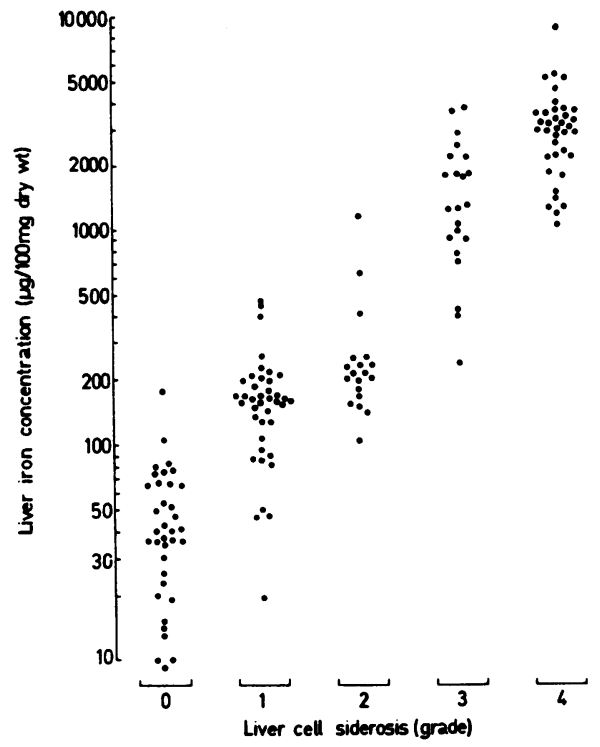

Fig 1 Relationship between liver iron concentration and stainable liver cell iron.

overlap. In only three biopsies were the values above $270 \mu \mathrm{g} / 100 \mathrm{mg}$.

The transition from grade 2 to grade 3 siderosis represented a marked increase in liver iron concentration. The mean value for biopsies with grade 3 siderosis was $1408 \mu \mathrm{g} / 100 \mathrm{mg}$ which was significantly higher than that for biopsies with grade 2 siderosis $(t=7.96, P<0.001)$. Except for three biopsies with lower values, liver iron concentration ranged from 703 to $3858 \mu \mathrm{g} / 100 \mathrm{mg}$; however, four of the six biopsies with values above $2000 \mu \mathrm{g} / 100$ mg were from heavily transfused patients with thalassaemia and showed heavy reticuloendothelial iron deposition.

Grade 4 siderosis corresponded to liver iron concentrations between 1023 and $8890 \mu \mathrm{g} / 100 \mathrm{mg}$. The mean value of $2727 \mu \mathrm{g} / 100 \mathrm{mg}$ was significantly higher than that for biopsies with grade 3 siderosis $(t=3.91 ; P<0.001)$.

\section{RELATION BETWEEN LIVER IRON CONCENTRATION AND TOTAL BODY STORAGE IRON}

There was a close linear relationship between the fall in liver iron concentration and the storage iron mobilized by venesection in patients with idiopathic haemochromatosis (fig 2). The regression slope indicates that liver iron concentration decreased by $167 \mu \mathrm{g} / 100 \mathrm{mg}$ dry liver for every gram of storage iron mobilized. The SE of the mean estimate for liver iron concentration on total iron stores was \pm $360 \mu \mathrm{g} / 100 \mathrm{mg}$. Reversing the roles of the variables,

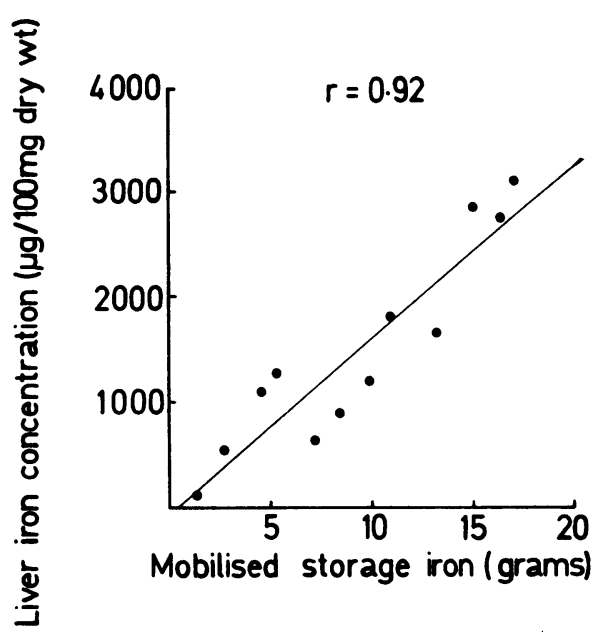

Fig 2 Relationship between the fall in liver iron concentration and mobilized storage iron in patients with idiopathic haemochromatosis. $y=167 x-70$

the $\mathrm{SE}$ of the mean estimate for total stores was \pm $2 \cdot 0$ grams.

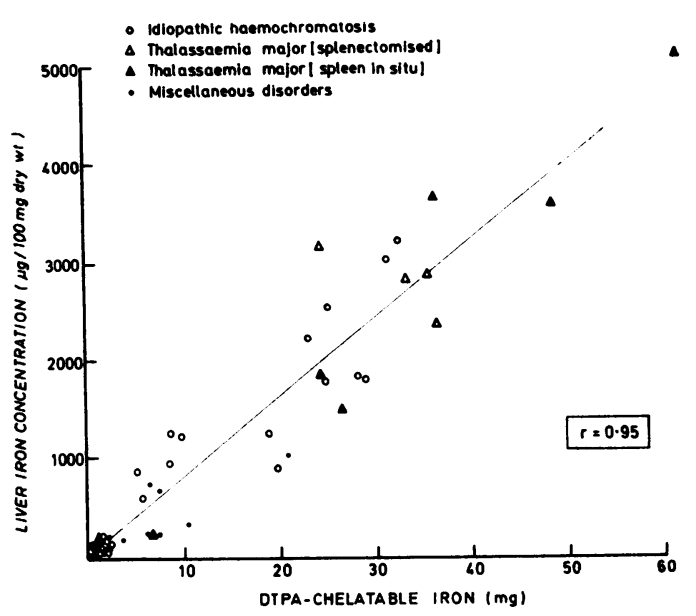

Fig 3 Relationship between liver iron concentration and DTPA-chelatable iron. $y=79.9 x-2 \cdot 7$

The relationship between liver iron concentration and DTPA-chelatable iron is shown in figure 3. From the regression slope it can be calculated that liver iron concentration increases by $173 \mu \mathrm{g} / 100 \mathrm{mg}$ dry liver/gram total body storage iron since it has been previously shown (Barry et al, 1970) that total storage iron increases by $0.46 \mathrm{~g} / \mathrm{mg}$ DTPA-chelatable iron.

\section{Discussion}

Even among western countries storage iron levels 
are subject to considerable geographical and racial variation, probably due to differences in the amounts of available iron in the diet (Charlton, Hawkins, Mavor, and Bothwell, 1970). Consequently, the definition of normal with regard to storage iron is a relative matter and has to be determined for each population in question. The observed range for liver total iron concentration in control males in this laboratory is $25-160 \mu \mathrm{g} / 100 \mathrm{mg}$ dry liver (mean 77 $\mu \mathrm{g} / 100 \mathrm{mg}$ ). Comparable values (corrected for dry weight) were obtained by Charlton et al (1970) in specimens from several other London hospitals and it would appear from their data that the London population is one with relatively low iron reserves.

The assessment of stainable iron is essentially subjective and the results will depend on the experience of the observer and the grading criteria employed. One of the disadvantages of the method is the lack of uniformity in grading criteria between different laboratories. The criteria used in this study have been fully described and illustrated elsewhere (Scheuer et al, 1962). They have been routinely employed in every biopsy taken at this hospital for more than a decade, are simple to apply, and are liable to little inter-observer variation. The criteria apply to parenchymal cell siderosis only and do not take into account reticuloendothelial iron deposits or iron in septa. The presence of disproportionately heavy reticuloendothelial or septal iron deposits in a few biopsies, eg, from patients with hepatitis or haemolytic states, or from patients with idiopathic haemochromatosis during treatment, accounts for the skew towards higher iron concentrations in most of the histochemical gradings.

The present findings show that there is a good correlation between stainable parenchymal cell iron and hepatic total iron concentration. Absence of stainable iron almost invariably corresponds to liver iron concentrations below the mean value for control London males and may therefore be regarded as indicating suboptimal iron stores. Weinfeld et al (1968) reached the same conclusion from a study of Swedish controls whose iron stores appear to be very similar to their London counterparts (Charlton et al, 1970). Grade 1 siderosis corresponds to liver iron levels in the upper half of the control range and to marginally elevated values while grade 2 siderosis generally represents only slightly more storage iron than grade 1 . The transition from grade 2 to grade 3 (submaximal) siderosis represents a marked increase in storage iron and occurs with tissue levels between 300 and $700 \mu \mathrm{g} / 100 \mathrm{mg}$ dry weight. Grade 3 siderosis always signifies increased liver iron concentration but the finding should be interpreted cautiously as the degree of excess can range from the relatively modest to the massive. It is only when grade 4 siderosis is present that massive iron excess can be safely assumed. There is probably a general tendency to overestimate the significance of stainable iron, especially when grades 2 and 3 siderosis are found; as these grades not infrequently occur in cirrhotics (particularly in alcoholics and patients with spontaneous or surgical shunts) the label of haemochromatosis may be inappropriately applied.

It should be noted that the relationship between liver iron concentration and stainable liver iron does not have a normal linear form. This may be explained by the varying distribution of iron between ferritin and haemosiderin at different iron loads. At low iron loads iron is predominantly held in ferritin which is water soluble and nonstainable. As the stores enlarge an increasing proportion is held as insoluble, stainable haemosiderin. In the rabbit (Shoden, Gabrio, and Finch, 1953) and in man (Shoden et al, 1953; Morgan and Walters, 1963) ferritin iron reaches a plateau when liver total iron concentration is in the range 500$1000 \mu \mathrm{g} / 100 \mathrm{mg}$ dry weight; at this point the iron fraction held in ferritin exceeds that in haemosiderin, but with further iron loading there is a sharp increase in haemosiderin which continues indefinitely.

There was a close correlation between liver iron concentration and measurements of total body storage iron obtained by (1) the definitive technique of quantitative phlebotomy in patients with haemochromatosis, and (2) indirectly by determination of DTPA-chelatable body iron in a variety of iron overload states. A similar correlation has been previously demonstrated between DTPA-chelatable iron and mobilizable storage iron in patients with haemochromatosis (Barry et al, 1970) and the present findings establish the close agreement between these three different methods of measuring storage iron. Liver iron concentration increases by approximately $170 \mu \mathrm{g} / 100 \mathrm{mg}$ dry tissue for every gram of total body storage iron, a general relationship applying in such diverse disorders as idiopathic haemochromatosis, cirrhosis with siderosis, and thalassaemia major with transfusional iron overload; moreover, in the thalassaemic patients there was no tendency for liver iron concentration to be higher, relative to DTPA-chelatable iron or total transfused load, in splenectomized subjects than in those with the spleen in situ. These observations suggest that the amount of iron held in the liver is, within limits, a fairly constant fraction of the total iron stores of the body, irrespective of the cause of the iron overload.

Technically, the determination of liver iron concentration is both simple and rapid, and falls well within the scope of most hospital laboratories. 
Large specimens are not demanded for the assay. Walker et al (1971) felt that the fragmented biopsies often obtained by the Menghini technique from patients with cirrhosis rarely provided sufficient material for both histological examination and chemical analysis. However, this has not been the present experience. When large amounts of iron are present relatively small specimens are in fact more convenient to process and, with accurate weighing facilities, fragments of less than $2 \mathrm{mg}$ dry weight present no difficulty; with low iron concentrations larger specimens are desirable though not essential. Moreover, it often happens that iron excess is not suspected until heavy siderosis is unexpectedly found on histological examination; under these circumstances, rather than subjecting the patient to a second liver biopsy, the remainder of the original specimen can be used for chemical analysis having first been freed from the block by dissolving the wax in xylene.

I am indebted to Dr Peter Scheuer for performing the histological examinations and to Professor Sheila Sherlock for her continued interest and support. Material was referred by many clinicians and pathologists to whom my thanks are also due.

References

Barry, M., Cartei, G. C., and Sherlock, S. (1969). Differential ferrioxamine test in haemochromatosis and liver disease. Gut, 10, 697-704.

Barry, M., Cartei, G.C., and Sherlock, S. (1970). Quantitative measurement of iron stores with diethylenetriamine penta-acetic acid. Gut, 11, 891-898.

Barry, M., and Sherlock, S. (1971). Measurement of liver iron concentration in needle-biopsy specimens. Lancet, 1, 100-103.

Chariton, R. W., Hawkins, D. M., Mavor, W. O., and Bothwell, T. H. (1970). Hepatic storage iron concentrations in different population groups. Amer. J. clin. Nutr., 23, 358-370.
MacDonald, R. A., and Pechet, G. S. (1964). Liver and tissue iron. Arch. Path., 77, 348-353.

MacDonald, R. A. (1967). Tissue iron and hemochromatosis. Arch. Path., 84, 543-551.

Morgan, E. H., and Walters, M. N. I. (1963). Iron storage in human disease: fractionation of hepatic and splenic iron into ferritin and haemosiderin with histochemical correlations. $J$. clin. Path., 16, 101-107.

Scheuer, P. J., Williams, R., and Muir, A. R. (1962). Hepatic pathology in relatives of patients with haemochromatosis. J. Path. Bact., 84, 53-64.

Shoden, A., Gabrio, B. W., and Finch, C. A. (1953). The relationship between ferritin and hemosiderin in rabbits and man. J. biol. Chem., 204, 823-830.

Wachstein, M. (1963). Cyto- and histochemistry of the liver. In The Liver: Morphology, Biochemistry and Physiology, edited by C. Rouiller, vol. 1. Academic Press, New York.

Walker, R. J., Miller, J. P. G., Dymock, I. W., Shilkin, K. B., and Williams, R. (1971). Relationship of hepatic iron concentration to histochemical grading and to total chelatable body iron in conditions associated with iron overload. Gut, 12, 10111014.

Weinfeld, A., Lundin, P., and Lundvall, O. (1968). Significance for the diagnosis of iron overload of histochemical and chemical iron in the liver of control subjects. J. clin. Path., 21, 35-40.

\section{Addendum}

Since this paper was submitted for publication Van Eijk, Wiltink, Bos, and Goosens (Clin. chim. Acta, 50, 1974, pp. 275-281) have suggested that the storage of liver in several widely used fixative solutions is associated with significant loss of iron from the specimen. To check this important point three wedge biopsies and one necropsy specimen, all of which had been previously analysed in thefresh state, were re-analysed after varying periods of preservation in $10 \%$ formalinphysiological saline solution. The results (table) do not indicate any significant iron loss over periods of storage ranging from five to 18 months in this particular medium which is routinely used in this hospital.

\begin{tabular}{|c|c|c|c|c|c|}
\hline \multirow[t]{3}{*}{ Specimen } & \multicolumn{4}{|c|}{ Liver Iron Concentration ( $\mu \mathrm{g} / 100 \mathrm{mg}$ dry weight) } & \multirow[t]{3}{*}{ Storage time (months) } \\
\hline & \multicolumn{2}{|l|}{ Fresh } & \multicolumn{2}{|c|}{ After Storage } & \\
\hline & Duplicates & Mean & Duplicates & Mean & \\
\hline 1 & $\begin{array}{l}2863 \\
3039\end{array}$ & 2951 & $\begin{array}{l}3277 \\
3543\end{array}$ & 3410 & 18 \\
\hline 2 & $\begin{array}{l}1528 \\
1453\end{array}$ & 1491 & $\begin{array}{l}1550 \\
1561\end{array}$ & 1556 & 5 \\
\hline 3 & $\begin{array}{l}1044 \\
1002\end{array}$ & 1021 & $\begin{array}{l}1216 \\
1117\end{array}$ & 1167 & 9 \\
\hline 4 & $\begin{array}{l}361 \\
372\end{array}$ & 367 & $\begin{array}{l}324 \\
337\end{array}$ & 331 & $7 \frac{1}{2}$ \\
\hline
\end{tabular}

Table The effect of storage in formol-saline on the iron content of liver biopsies 